\title{
Determinants of appetite ratings: the role of age, gender, BMI, physical activity, smoking habits, and diet/weight concern
}

\author{
Nikolaj T. Gregersen'*, Bente K. Møller², Anne Raben', \\ Søren T. Kristensen ${ }^{3}$, Lotte Holm ${ }^{1,4}$, Anne Flint ${ }^{5}$ and \\ Arne Astrup'
}

'Department of Human Nutrition, Faculty of Life Sciences, University of Copenhagen, Frederiksberg, Denmark; ${ }^{2}$ Municipal of Aarhus, Department for Children and Young People (Health and Wellfare), Viby, Denmark; ${ }^{3}$ Metropolitan University College, Department of Nutritional Health, Copenhagen, Denmark; ${ }^{4}$ Faculty of Life Sciences, Institute of Food and Resource Economics, University of Copenhagen, Frederiksberg, Denmark; ${ }^{5}$ Department of Human Nutrition, The Royal Veterinary and Agricultural University, Novo Nordisk A/S, Søborg, Copenhagen, Denmark

Abstract

Background: Appetite measures are often recorded by visual analogue scales (VAS), and are assumed to reflect central nervous system (CNS) perceptions and sensations. However, little is known about how physiological, psychological, social, and cultural factors influence VAS.

Objective: To investigate whether age, gender, body mass index (BMI), smoking habits, physical activity, diet behaviour, and menstruation cycle are determinants of appetite ratings.

Design: We investigated appetite ratings in different groups of a population during a single meal test, including 178 healthy women (98) and men (80), aged 20-60 years with a BMI of $18.5-35.0 \mathrm{~kg} / \mathrm{m}^{2}$. Subjects consumed an evening meal composed to meet individual requirements of energy content and recommendations regarding macronutrient composition. Before and every half hour until 3 hours after the meal, subjects filled out VAS for satiety, fullness, hunger, and prospective food intake. They also filled in a questionnaire on eating/slimming behaviour.

Results: Multiple linear regression analyses showed that gender and age were the most powerful predictors of postprandial satiety $\left(p<0.001\right.$, adj. $\left.R^{2}=0.19\right)$ and hunger $\left(p<0.001\right.$, adj. $\left.R^{2}=0.15\right)$. Repeated measures general linear model (GLM) analyses revealed that women felt more satisfied than men $(p<0.001)$ and older subjects felt more satisfied than younger $(p<0.01)$. Furthermore, light/no exercisers felt more satisfied and less hungry than hard/moderate exercisers $(p<0.05)$, but these differences disappeared after adjusting for age and gender. Smokers rated their prospective consumption lower than non-smokers $(p<005)$ and women in the ovulation phase felt less hungry than women in the menstruation phase $(p<005)$. Neither BMI nor diet/weight concern were significantly associated with appetite ratings.

Conclusions: Appetite ratings differed according to age, gender, and physical activity and to a lesser degree for smoking habits and menstruation cycle. Appetite ratings were not influenced by BMI and diet/weight concern. These factors should be considered when planning studies and analysing data concerning appetite sensations.

Keywords: appetite sensations; physiological determinants; psychological factors

Received: 9 March 20II; Revised: 23 June 201।; Accepted: I July 20II; Published: II August 20 I I

$\mathrm{W}$ ith the worldwide increasing prevalence of obesity, the health-related and socio-economic problems increase likewise (1) leaving a need

At the time of the study, Anne Flint was employed at the Department of Human Nutrition, The Royal Veterinary and Agricultural University, Copenhagen. for effective strategies to prevent and reduce overweight and obesity.

The mechanisms underlying the regulation of energy intake and appetite are complex and work together in a redundant system. Thus, physiological as well as psychological, social and cultural factors influence appetite (2-4). Studies have also found different appetite 
experiences between different population groups. Older subjects experience less hunger than younger $(5,6)$, a negative association has been found between dietary restraint and hunger (7), and women show a desire for something sweet more often than men (8). However, such studies are usually carried out with a limited number of subjects, which makes the statistics less powerful. Flint and associates found that using an unpaired design at least 22 subjects in each group were needed to detect a difference of $10 \%$ on mean 4.5 hour ratings of appetite measured on a Visual Analogue Scale (VAS) of $10 \mathrm{~cm}$ (9).

To our knowledge, the group differences mentioned have not been investigated in a larger population. Thus the objective of the present study was to investigate whether age, gender, BMI, smoking habits, physical activity levels, diet behaviour, and menstruation cycle (for women) are determinants of appetite ratings in an urban population of about 200 subjects in order to confirm or refute the findings of previous studies on smaller populations. We hypothesised that subjects would experience different sensations of appetite after intake of a standardised meal due to differences in physiological and non-physiological factors.

\section{Materials and methods}

\section{Subjects}

A Copenhagen cohort of 1,246 subjects representing an average urban population was approached by telephone by a marketing bureau (Jysk Analyseinstitut A/S, Aalborg, Denmark). Subjects were included if they were willing to participate, healthy, 20-60 years of age, had a BMI of $18.5-35.0 \mathrm{~kg} / \mathrm{m}^{2}$ and had no extraordinary eating habits (e.g. vegetarians). The aim was to include 200 subjects representative of the Danish population according to gender, age, educational, and employment status as well as household composition. A total of 334 subjects fulfilled the inclusion criteria and were interested in participating in the study and were therefore invited. Of the invited subjects, 147 did not show up, meaning that a total of 187 subjects finally participated in the investigation. The subjects that did not show up did not differ from the ones that participated in any of the variables known from the telephone interview (information on gender, age, body weight, height, and level of physical activity). Due to missing values nine subjects were excluded (seven subjects lacked VAS scores and two subjects did not fast for 4 hours), leaving complete sets of data from 178 subjects to be analysed (Table 1). This study was conducted according to the guidelines laid down in the Declaration of Helsinki and all procedures involving human subjects were approved by the Municipal Ethical Committee of Copenhagen and Frederiksberg. Written informed consent was obtained from all

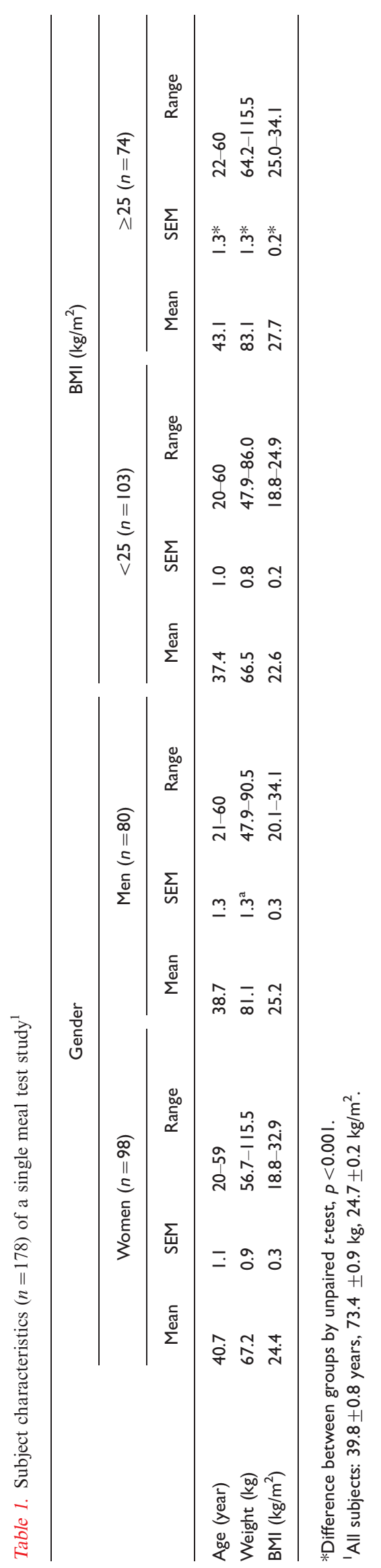


subjects. The study was conducted before registration in www.clinicaltrials.gov was required.

\section{Protocol}

The participants were invited for an evening test meal at the Department of Human Nutrition, Copenhagen. The meal test was part of a cross-disciplinary project 'SOCIOMAET - physiological and socio-cultural aspects of appetite,' which was designed and carried out at the Department of Human Nutrition, Faculty of Life Sciences, University of Copenhagen, Denmark. The evening meal was tested by all subjects in groups of 10 30 subjects per test day. Subjects arrived at 1700 hours after 4 hours of fasting. After voiding, the subjects were weighed (Lindeltronic 800C, Frederiksberg Vægtfabrik, Copenhagen, Denmark, accuracy of $0.05 \mathrm{~kg}$ ) and height was measured (light clothes and no shoes). Then the participants were seated in self-selected groups of 4-6. Before intake of the evening meal and every half hour until 3 hours after the meal, the subjects rated appetite sensations using VAS (9). The meal was given at 1730 hours and subjects were asked to consume it within half an hour. Subjects were instructed to eat the whole meal, but not all were able to do so. In these cases the leftovers were weighed and the amount of each meal component was noted for later data analyses. Subjective palatability ratings of the meal using VAS were made right after meal intake. Smoking was allowed after the meal. During the evening the subjects filled out a questionnaire on living and eating habits, weight concerns, and other relevant information.

\section{Test meal}

The meal was prepared in our experimental kitchen and composed to meet the Nordic Nutrition Recommendations (10) with a carbohydrate content of 60 energy percent (E\%), $15 \mathrm{E} \%$ protein, $25 \mathrm{E} \%$ fat, and $3.0 \mathrm{~g} / \mathrm{MJ}$ of dietary fibre. It was a typical Danish evening meal in which the amount of energy contributed to $35 \%$ of the individual daily energy requirement (DER) (11). The DER was estimated using self-reported information on gender, age, weight, height, and level of physical activity (12). Subjects reported physical activity level as light, moderate, or heavy. In the 1985 report 'Energy and protein requirements' by $\mathrm{FAO} / \mathrm{WHO} / \mathrm{UNU}$ (12), equations are given in annex one to predict the basal metabolic rate (BMR) from weight, height, age, and gender. To find the average individual DER, the BMR was multiplied with a factor based on the physical activity level Table 15 in this report (12). Thus the portion size and energy content, but not the composition of the meal, differed among individuals. The meal consisted of a hot pot with turkey meat, green pepper, onion, purée of tomato, and cream served with parboiled rice, bread, and a salad (green salad, cucumber, leek, tomato, and carrot) with salad dressing. Additionally $150 \mathrm{ml}$ of tap water was served.

\section{Questionnaires}

The appetite and palatability ratings were measured using $10 \mathrm{~cm}$ VAS booklets (one question per page) (9). Appetite was expressed by terms of hunger, satiety, fullness, and prospective consumption, a high rating indicating, for example, a strong sensation of hunger or satiety. The palatability of the meal was measured once immediately after the meal by rating overall impression, taste, aftertaste, smell, and appearance (low rating is positive, except for after-taste where low rating is negative).

The questionnaire filled in during the evening was a specifically designed multiple-choice questionnaire developed by the investigators. The questions treated in this paper described the participants' diet/weight concern, smoking, and physical activity level. To get an overall impression of the subjects diet/weight concern and to reduce the risk of type I errors due to a large number of analyses, answers to the following questions were pooled: How often do you think about the amount of calories in your food? (Very often, often, seldom, never); How often do you try to regulate your body weight? (Very often, often, seldom, never); How often are you on a diet? (Very often, often, seldom, never); Do you try to avoid fat-rich foods? (Very often, often, seldom, never); Do you eat less than you desire? (Very often, often, seldom, never); Do you have difficulties keeping your weight down? (Agreeing, partly agreeing, partly disagreeing, disagreeing); Have you ever been on a diet and lost more than $5 \mathrm{~kg}$ ? (Yes, no). A rating of the diet/weight concern was constructed by giving each answer a value. The most positive answers (very often, agreed, and yes) were given the highest value $(4,4$, and 2 , respectively), and the most negative answers were given a value of 1 . Values to all questions were added individually. Thus, a high rating indicated a high degree of diet/weight concern. Subjects were divided into smokers and non-smokers. Smokers were subjects who smoked daily, frequently, or occasionally. Non-smokers were defined as subjects who had never smoked or had stopped smoking.

The habitual physical activity levels were divided into hard/moderate exercise and light/no exercise. Hard/moderate exercisers were training hard several times a week or training at least 4 hours weekly. Light/no exercisers were subjects who exerted light exercise (walking, cycling) at the most 4 hours weekly or not at all. These categories were made to provide a sufficient number of subjects in each group and to give the statistical analyses sufficient power.

\section{Data analyses}

All data are expressed as mean \pm SEM. All analyses were carried out using SPSS for Windows (version 11.5, SPSS 
Inc, Chicago, Illinois). Differences in ratings of meal palatability (overall impression, taste, after-taste, smell, and appearance) between groups were analysed using a one-way ANOVA. As groups, we used gender (male, female), age (20-30 years, 31-40 years, 41-50 years, 51-60 years), BMI (normal weight $<25 \mathrm{~kg} / \mathrm{m}^{2}$, overweight $\geq 25$ $\mathrm{kg} / \mathrm{m}^{2}$ ), physical activity level (hard/moderate exercise, light/no exercise), smoking habits (smokers, non-smokers), diet/weight concerns (light 7-10, moderate 11-15, high 16-19), consumed food (all, leftovers), and for women period of menstruation cycle (around ovulation [day 11-18], around menstruation). Overall impression, taste, smell, and appearance were square-rooted and after-taste squared to obtain normal distribution. The associations between appetite ratings and overall impression of the meal were analysed by simple linear regression. Since $p>0.05$, overall impression of the meal was not used as a covariate in the following analyses.

The differences in mean energy and macronutrient intake between subjects who consumed the whole meal and subjects with leftovers $(n=60)$ were analysed using unpaired $t$-test. Since there were statistically significant difference in mean energy and macronutrient intake between subjects, we used individual relative energy intake (actual energy intake related to calculated energy intake in percentages) as a covariate. Furthermore, we analysed if the subjects who did not eat everything differed in any of the chosen explanatory variables from the rest of the subjects. This was done using nonparametric Pearson's Chi-square test. As we found no differences between these two groups, we included all subjects in the analyses. Differences in appetite ratings (VAS) between groups were analysed using GLM for repeated measurements of appetite ratings over time, with fasting value and relative energy intake as covariates. Secondary analyses on physical activity level were made with age and gender as additional covariates. Multiple comparisons were based on estimated marginal means and Bonferroni adjustments.

In search of a model explaining most of the variation in the postprandial means of appetite ratings (squared), we used backwards multiple linear regressions with different groups and continuous data significantly related to the appetite ratings as explanatory variables. Adjusted $R^{2}$ was used to describe the percentage of variation explained by the variables. This $R^{2}$ is adjusted for the number of variables and data in the regression model and is therefore more conservative than the unadjusted $R^{2}$. Statistical significance was set at $p<0.05$.

\section{Results}

\section{Energy and macronutrient intake}

Of the 178 subjects, a total of 60 did not consume the whole meal. This resulted in differences in mean energy intake $(4104 \pm 83$ vs. $3310 \pm 141 \mathrm{~kJ}, p<0.001)$, protein intake $(14.40 \pm 0.00$ vs. $14.36 \pm 0.02 \mathrm{E} \%, p<0.05)$, fat intake $(24.9 \pm 0.0$ vs. $24.4 \pm 0.2 \mathrm{E} \%, \mathrm{p}<0.05)$, and intake of dietary fibre $(11.8 \pm 0.2$ vs. $8.7 \pm 0.3 \mathrm{~g}, p<0.001)$, but not carbohydrate intake $(60.1 \pm 0.0$ vs. $60.6 \pm 0.3 \mathrm{E} \%, p=$ 0.057 ) between the subjects that consumed the entire meal and the ones that did not, respectively.

\section{Evaluation of the test meal}

Overall the meal was rated as palatable $(2.6 \pm 0.2 \mathrm{~cm})$. Furthermore, the taste $(2.4 \pm 0.1 \mathrm{~cm})$, after-taste $(8.6 \pm 0.1$ $\mathrm{cm})$, smell $(2.7 \pm 0.2 \mathrm{~cm})$, and appearance $(2.6 \pm 0.2 \mathrm{~cm})$ of the meal were also rated to be appetising. No differences in meal evaluation between groups were observed $(p>0.05)$.

Differences in postprandial appetite ratings between groups Group differences in postprandial appetite ratings of satiety and fullness are shown in Table 2 and data of hunger and prospective consumption are shown in Table 3. Figs. 1, 2, and 3 illustrates appetite ratings between groups (one per group), where group $\times$ time effects were found. We found no significant differences in appetite ratings between subjects who consumed the whole meal and subjects with leftovers $(p>0.10)$.

\section{Gender}

There was an interaction between time and gender for measures of hunger (Table 3). Fig. 1 shows that the increase in postprandial hunger ratings for men was steeper than for women. There were significant differences between genders for mean values of all appetite parameters (Tables 2 and 3). Thus, women had significantly higher satiety and fullness ratings than men and lower ratings of hunger and prospective consumption.

\section{Age}

There were interactions between time and age for satiety (Fig. 2), fullness, hunger, and prospective consumption (Tables 2 and 3). Subjects aged 20-30 years were less satisfied than subjects aged 41-60 years (Table 2). Likewise, subjects aged 20-40 years were less full and hungrier than subjects aged 41-60 years (Tables 2 and 3). Furthermore, the ratings of prospective consumption were higher in subjects aged 20-40 years than in subjects aged 41-50 years and higher in subjects aged $31-40$ years than in the subjects aged 51-60 years (Table 3). In addition, subjects aged 41-60 years remained satisfied and full longer, developed hunger slower, and rated their prospective food consumption lower than subjects aged 20-40 years (Fig. 2). Altogether this indicates that as age increased postprandial hunger and desire to eat decreased. 
Table 2. Differences in postprandial (4 hours) ratings of satiety and fullness between groups in a single meal test ${ }^{1}$

\begin{tabular}{|c|c|c|c|c|c|c|c|c|c|c|c|}
\hline & \multirow[b]{3}{*}{ Group } & \multicolumn{5}{|c|}{ Satiety } & \multicolumn{5}{|c|}{ Fullness } \\
\hline & & \multirow[b]{2}{*}{$n$} & \multirow[b]{2}{*}{ Mean } & \multirow[b]{2}{*}{ SEM } & \multicolumn{2}{|c|}{$p$ (ANOVA) } & \multirow[b]{2}{*}{$N$} & \multirow[b]{2}{*}{ Mean } & \multirow[b]{2}{*}{ SEM } & \multicolumn{2}{|c|}{$P$ (ANOVA) } \\
\hline & & & & & Group $\times$ time & Group & & & & Group $\times$ time & Group \\
\hline \multirow[t]{2}{*}{ Gender } & Female & 97 & 8.2 & 0.15 & NS & $<0.001$ & 97 & 8.1 & 0.16 & NS & $<0.001$ \\
\hline & Men & 78 & 7.3 & 0.17 & & & 77 & 7.1 & 0.18 & & \\
\hline \multirow[t]{4}{*}{ Age (years) } & $20-30$ & 43 & 7.3 & $0.23^{\mathrm{a}}$ & $<0.001$ & 0.002 & 43 & 7.1 & $0.24^{\mathrm{a}}$ & $<0.001$ & 0.001 \\
\hline & $3 I-40$ & 50 & 7.5 & $0.21^{\mathrm{ac}}$ & & & 50 & 7.3 & $0.22^{\mathrm{a}}$ & & \\
\hline & $4 I-50$ & 45 & 8.3 & $0.23^{\mathrm{bc}}$ & & & 45 & 8.2 & $0.24^{\mathrm{b}}$ & & \\
\hline & $51-60$ & 37 & 8.3 & $0.25^{\mathrm{bc}}$ & & & 36 & 8.3 & $0.27^{b}$ & & \\
\hline \multirow[t]{2}{*}{ BMI $\left(\mathrm{kg} / \mathrm{m}^{2}\right)$} & $<25$ & 103 & 7.7 & 0.16 & NS & NS & 103 & 7.6 & 0.16 & NS & NS \\
\hline & $\geq 25$ & 72 & 7.1 & 0.19 & & & 7I & 7.8 & 0.20 & & \\
\hline \multirow[t]{2}{*}{ Physical activity level } & Hard/moderate exercise & 46 & 7.4 & 0.23 & NS & 0.049 & 46 & 7.3 & 0.24 & NS & NS \\
\hline & Light/no exercise & 129 & 7.9 & 0.14 & & & 128 & 7.8 & 0.14 & & \\
\hline \multirow[t]{2}{*}{ Smoking habits } & Smoker & 59 & 8.0 & 0.21 & NS & NS & 59 & 7.9 & 0.21 & 0.004 & NS \\
\hline & Non-smoker & 115 & 7.7 & 0.14 & & & 114 & 7.6 & 0.15 & & \\
\hline \multirow[t]{3}{*}{ Diet/weight concern } & Light & 48 & 7.5 & 0.23 & NS & NS & 48 & 7.4 & 0.23 & NS & NS \\
\hline & Moderate & 77 & 7.8 & 0.20 & & & 76 & 7.7 & 0.19 & & \\
\hline & Heavy & 45 & 8.2 & 0.24 & & & 45 & 8.1 & 0.24 & & \\
\hline Period of menstruation & Around menstruation & 45 & 7.9 & 0.25 & NS & NS & 45 & 7.8 & 0.24 & NS & NS \\
\hline Cycle & Around ovulation & 25 & 8.5 & 0.34 & & & 25 & 8.3 & 0.33 & & \\
\hline
\end{tabular}

NS: non-significant.

Different superior letters ( $a, b$, and $c$ ) indicate significant different means.

'Based on Bonferroni adjusted estimated marginal mean (mean) from repeated measurement analyses (ANOVA) of postprandial VAS scores with fasting value and relative energy intake as cofactors. All analyses showed significant time effect $(p<0.00 \mathrm{I})$.

\section{$B M I$ and body weight}

According to the GLM analyses, there were no differences in appetite ratings between normal weight and overweight subjects (Tables 2 and 3).

\section{Physical exercise}

Hard/moderate exercisers showed a lower mean rating of satiety and higher mean ratings of hunger and prospective consumption than light/non-exercisers (Tables 2 and 3). With age and gender as additional covariates, the differences became insignificant $(p>0.05)$.

\section{Smoking}

The statistical analyses showed a time by smoking interaction for satiety and fullness (Fig. 3). Smokers were satisfied and full longer (Table 2) and rated prospective consumption lower than non-smokers did (Table 3).

\section{Diet/weight concerns}

We observed no differences in satiety, fullness, hunger, and prospective consumption ratings between groups with different diet/weight concerns (Tables 2 and 3).

\section{Menstruation cycle}

Hunger ratings differed according to period of menstruation cycle (Table 3 ). Thus, women around menstruation had higher postprandial hunger ratings than women around ovulation. Backwards multiple linear regression analyses showed that gender and age were two of the variables that explained most of the variation in satiety $\left(p<0.001\right.$, adj. $\left.R^{2}=0.19\right)$, fullness $\left(p<0.001\right.$, adj. $R^{2}=$ $0.18)$, hunger $\left(p<0.001\right.$, adj. $\left.R^{2}=0.15\right)$, and prospective consumption $\left(p<0.001\right.$, adj. $\left.R^{2}=0.15\right)$.

\section{Discussion}

The findings of our study showed that postprandial appetite sensations are experienced differently by different groups in a population. We found that groups with different gender, age, and smoking habits, as well as period in menstruation cycle reported different appetite sensations after an identical energy-balanced meal. However, no differences in appetite sensations were seen between groups varying in BMI, physical activity, and diet/weight concerns.

Women rated hunger and prospective consumption lower and satiety and fullness higher than men did by approximately $1 \mathrm{~cm}(10 \%)$. Similar findings has been reported in a smaller study group testing four different 
Table 3. Differences in postprandial (4 hours) ratings of hunger and prospective consumption between groups in a single meal test ${ }^{1}$

\begin{tabular}{|c|c|c|c|c|c|c|c|c|c|c|c|}
\hline & \multirow[b]{3}{*}{ Group } & \multicolumn{5}{|c|}{ Hunger } & \multicolumn{5}{|c|}{ Prospective consumption } \\
\hline & & \multirow[b]{2}{*}{$n$} & \multirow[b]{2}{*}{ Mean } & \multirow[b]{2}{*}{ SEM } & \multicolumn{2}{|c|}{$P$ (ANOVA) } & \multirow[b]{2}{*}{$N$} & \multirow[b]{2}{*}{ Mean } & \multirow[b]{2}{*}{ SEM } & \multicolumn{2}{|c|}{$P$ (ANOVA) } \\
\hline & & & & & Group $\times$ time & Group & & & & Group $\times$ time & Group \\
\hline \multirow[t]{2}{*}{ Gender } & Female & 97 & 1.3 & 0.14 & 0.009 & $<0.001$ & 97 & 1.5 & 0.14 & NS & $<0.001$ \\
\hline & Men & 78 & 2.5 & 0.15 & & & 76 & 2.6 & 0.16 & & \\
\hline \multirow[t]{4}{*}{ Age (years) } & $20-30$ & 43 & 2.2 & $0.21^{\mathrm{a}}$ & $<0.001$ & $<0.001$ & 43 & 2.3 & $0.21^{b c}$ & 0.001 & $<0.001$ \\
\hline & $31-40$ & 50 & 2.4 & $0.20^{\mathrm{a}}$ & & & 50 & 2.5 & $0.19^{b}$ & & \\
\hline & $4 I-50$ & 45 & 1.3 & $0.21^{\mathrm{b}}$ & & & 44 & 1.2 & $0.21^{\mathrm{a}}$ & & \\
\hline & $51-60$ & 37 & 1.3 & $0.23^{\mathrm{b}}$ & & & 36 & 1.5 & $0.23^{\mathrm{ca}}$ & & \\
\hline \multirow[t]{2}{*}{ BMI $\left(\mathrm{kg} / \mathrm{m}^{2}\right)$} & $<25$ & 103 & 1.9 & 0.14 & NS & NS & 102 & 2.0 & 0.14 & NS & NS \\
\hline & $\geq 25$ & 72 & 1.8 & 0.17 & & & 71 & 1.9 & 0.17 & & \\
\hline \multirow[t]{2}{*}{ Physical activity level } & Hard/moderate exercise & 46 & 2.7 & 0.21 & NS & 0.020 & 46 & 2.5 & 0.21 & NS & 0.004 \\
\hline & Light/no exercise & 129 & 1.7 & 0.13 & & & 127 & 1.8 & 0.12 & & \\
\hline \multirow[t]{2}{*}{ Smoking habits } & Smoker & 59 & 1.5 & 0.19 & NS & NS & 58 & 1.7 & 0.19 & NS & 0.040 \\
\hline & Non-smoker & 115 & 2.0 & 0.14 & & & 114 & 2.1 & 0.13 & & \\
\hline \multirow[t]{3}{*}{ Diet/weight concern } & Light & 48 & 2.2 & 0.21 & NS & NS & 46 & 2.4 & 0.21 & NS & NS \\
\hline & Moderate & 77 & 1.8 & 0.17 & & & 77 & 2.0 & 0.16 & & \\
\hline & Heavy & 45 & 1.5 & 0.22 & & & 45 & 1.6 & 0.21 & & \\
\hline Period of menstruation & Around menstruation & 45 & 1.6 & 0.18 & NS & 0.043 & 45 & 1.8 & 0.18 & NS & NS \\
\hline Cycle & Around ovulation & 25 & 1.0 & 0.24 & & & 25 & 1.2 & 0.24 & & \\
\hline
\end{tabular}

NS: non-significant.

Different superior letters (a, b, and c) indicate significant different means.

'Based on Bonferroni adjusted estimated marginal mean (mean) from repeated measurement analyses (ANOVA) of postprandial VAS scores with fasting value and relative energy intake as cofactors. All analyses showed significant time effect $(p<0.00 \mathrm{I})$. 


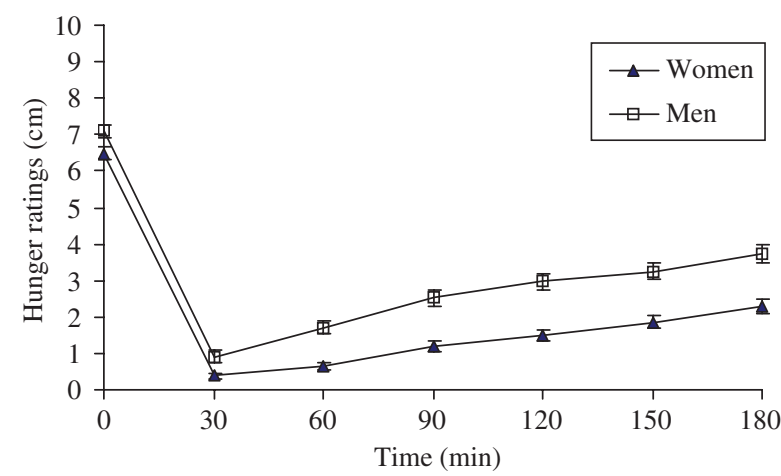

Fig. 1. Mean $( \pm$ SEM) ratings of hunger in 97 women and 78 men before $(0 \mathrm{~min})$ and after intake of a hot evening meal adjusted to $35 \%$ of daily individual energy requirements. By repeated measurement analysis, we found a time by gender effect $(p=0.009)$ and different hunger ratings based on estimated marginal means $(p<0.001)$.

meals that had comparable energy densities but were high in carbohydrate, fat, protein, or alcohol, respectively (13). An explanatory factor might be the difference in concentration of sex hormones like estradiol, which influences areas in the hypothalamus controlling eating behaviour and thus appetite regulation. It has been demonstrated that estradiol increases the satiating power of endogenous cholecystokinin (14), and therefore the higher concentrations of estradiol in women might be partly responsible for their lower hunger and higher satiety ratings. Estradiol concentrations also vary during the menstruation cycle. In accordance with this we found differences in hunger ratings between women in different periods of their menstruation cycle. Additionally, one study in which PET scans were used to investigate neuroanatomical responses to hunger and satiation, showed extensive similarities as well as differences in activity in specific brain areas between genders (15).

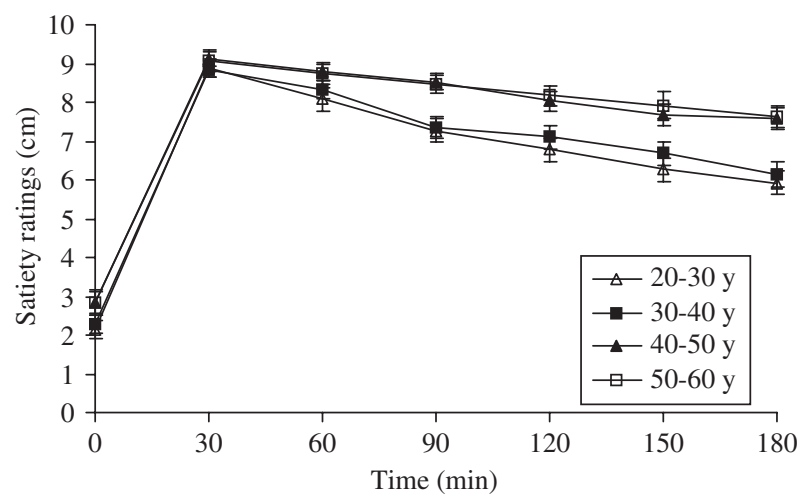

Fig. 2. Mean $( \pm$ SEM) ratings of satiety in 175 subjects divided into four age groups before $(0 \mathrm{~min})$ and after intake of a hot evening meal adjusted to $35 \%$ of daily individual energy requirements. By repeated measurement analysis, we found a time by age effect $(p<0.001)$ and different satiety ratings based on estimated marginal means $(p=0.002)$.

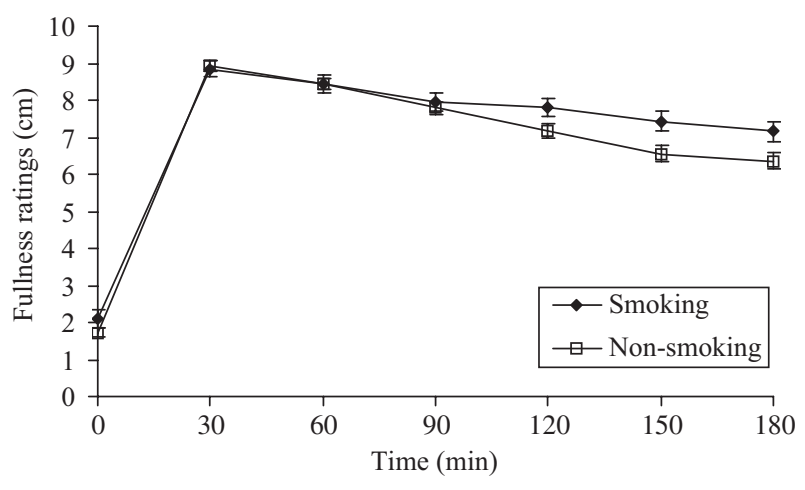

Fig. 3. Mean ( \pm SEM) ratings of fullness in 174 subjects divided into smoking habits before $(0 \mathrm{~min})$ and after intake of a hot evening meal adjusted to $35 \%$ of daily individual energy requirements. By repeated measurement analysis, we found a time by smoking effect ( $p=0.004)$ but no difference in fullness ratings based on estimated marginal means $(p>$ $0.05)$.

These findings are supported by other studies $(16,17)$ and indicate gender specific differences in the cognitive and emotional processing of hunger and satiation. One of these studies also showed a higher degree of dietary restraint in women (16). However, the degree of dietary restraint did not correlate with food intake (16).

The present study showed that older subjects rated hunger and prospective consumption lower and satiety and fullness higher than younger subjects, and that these age-related alterations occurred at an early age. This confirms the results of other studies that found that ageing leads to a decline in food intake, a phenomenon often referred to as anorexia of aging $(5,6)$. This might be due to loss of taste and smell in older compared to younger subjects resulting in less responsiveness to appetite cues $(6,18)$, but also to an increase in the activity of the peripheral satiation system (19). Another study found that healthy older persons were less hungry and more full before a standard meal and became more quickly satiated after a standard meal than younger persons (20). This was partly explained by the sensitivity to the satiating effect of cholecystokinin being retained in older persons and endogenous cholecystokinin concentrations being higher than in younger persons, thus resulting in decreased appetite ratings and energy intake (20). Another difference between older and younger male subjects was found using intraduodenal infusions of glucose, which resulted in decreased energy intake in older but not in younger men (21).

Our results showed no differences in appetite ratings between normal weight and overweight persons. However, previously it has been proposed that overweight persons overeat as a result of dysregulation of appetite (22). This was supported by a study showing that obese men were more prone to passive over-consumption 
compared to lean men after intake of a high-fat preload. Nevertheless, following a low-fat preload there were no differences in energy intake between obese and lean men (23). In our study we served a medium-fat meal and, based on the study by Speechly and Buffenstein (23), such a meal may not reveal any differences in appetite scores between normal weight and overweight subjects. The implication could be that overweight subjects will be fully satiated on this type of meal (composed according to the recommendations) and thus that the potential differences between normal weight and overweight subjects would be eliminated. Nevertheless, more studies are needed to disentangle the potential associations between BMI and appetite.

Unadjusted analyses showed that hard/moderate exercisers had higher ratings of hunger and prospective consumption than light/non-exercisers. This was unexpected because the size of the meal was calculated to meet the individual requirements also according to physical activity level. Furthermore, acute exercise has been shown to decrease 24-hour levels of leptin and insulin and increase PYY levels (24), which would then suggest a positive correlation between exercise and satiety and thus conflict with our findings. Nevertheless, whether these acute effects translate into similar long-term effects (in the absence of weight loss) is not clear. In addition, there is considerable individual variation in appetite response to exercise (25).

Furthermore, when analysing the data further we found that the majority of subjects in the category of hard/moderate exercisers were men, who rated hunger and prospective consumption higher than women. When using gender and age as covariates in the analyses, we found that the difference between the study groups of habitual physical activity level became insignificant. Thus, gender and age but not physical activity level explained the difference in hunger and prospective consumption. In other words, if physical activity (in contrast to our findings) is in fact related to appetite sensations then this association may be masked by large individual variation.

Our study showed that the declines of satiety and fullness were slower for smokers than for non-smokers. This is in agreement with another study showing that nicotine suppresses hunger, increases satiety, and reduces energy intake (26). Although the understanding of the mechanisms behind the reduced appetite in smokers is still limited, recent studies suggest that stimulation of both central, i.e. pro-opiomelanocortin (POMC) receptors (27), and peripheral factors, i.e. gastric emptying (28) are involved. Finally, in spite of the literature being rather consistent in showing a negative association between smoking and hunger, a recent review has highlighted that heavy smokers have a greater body weight compared to light smokers, and that this may be due to a clustering of risk factors in heavy smokers (29). Thus, this needs to be taken into consideration when studying the relation between smoking and appetite.

No associations between diet/weight concern and appetite ratings were seen in our study. This result may be due to the specific menu and context of the test meal. In another sub-study of 'SOCIOMAET' the experience and handling of appetite in an everyday life context was analysed based on qualitative in-depth interviews with 20 subjects (30). In this sub-study appetite sensations were influenced by the social and cultural context in which meals were taken, as well as by individual perceptions of body weight and diet concern (30).

An interesting result of our study was that when using the recommended macronutrient composition of a meal (10) and serving a meal size with $35 \%$ of subjects' daily energy needs (e.g. equal to the average energy intake at dinner in Denmark), one-third of the subjects were unable to finish the meal. As this might influence the appetite scores, we sought to adjust for this by using the relative energy intake as a covariate. The rating of appetite showed that satiety and fullness lasted longer and did not return to initial levels during the three postprandial hours of the test. This suggests that the recommended diet used in the present study can be used to reduce total energy intake, as has been demonstrated in several previous studies (31-33).

Our study showed an almost 20\% lower energy intake in the subjects that did not consume the whole meal compared to the subjects that did, but still the differences in macronutrient intake (in $\mathrm{E} \%$ ) were only marginal (although still significant for protein and fat). This can be explained by the large sample size and the fact that the test meal was a homogeneous hot pot and thus that the macronutrient composition was designed to be identical in the whole pot. Together these factors yielded very low SEMs for the macronutrient intakes, which ultimately lead to very small numerical differences being significantly different.

The individual energy requirements are based on selfreported data on height, weight, and physical activity level. It has been shown that people tend to over-report height and physical activity level and under-report weight when asked (34). This could result in errors in the estimated portion size of the test meal and, as a result, affect the postprandial appetite scores. Additionally, the WHO-based (12) equations used to predict energy requirements may not be equally precise for all subjects, and this variation may therefore also have influenced differently on the subjective appetite scores. Furthermore, although commensality was part of the study design, the context in which subjects are offered the meal is different to their daily habitual dining situation and this could possibly affect the appetite scores as well. Finally, although the large sample size in our study is a major 
strength compared to the existing evidence, it cannot compensate for the fact that subjects with higher BMI are more prone to under-reporting than subjects with lower BMI (35).

\section{Conclusion}

In conclusion, our results showed that appetite sensations after an energy-balanced meal were associated with mainly age, gender, and smoking habits but not physical activity level, diet/weight concern, and BMI. Nevertheless, the phenomenon of appetite may still benefit from being studied as a cross-disciplinary field of investigation including both physiological and non-physiological factors. Thus, both demographic and socio-cultural variables potentially associated with appetite sensations should be considered when planning intervention studies within appetite research.

\section{Conflict of interest and funding}

At the time of the study, AF was employed at the Department of Human Nutrition, The Royal Veterinary and Agricultural University, Copenhagen. Now AF is employed at Novo Nordisk A/S, a company that manufactures and markets pharmaceuticals related to the treatment of diabetes and its complications.

None of the other authors have any conflict of interest. The study was financially supported by The Danish Research Councils, \# 9600266.

\section{References}

1. WHO (2000): Obesity: preventing and managing the global epidemic. Report of a WHO consultation. Technical Report Series, No. 894. Geneva: Author.

2. Blundell JE, Rogers PJ. Hunger, hedonics, and the control of satiation and satiety. In: Friedman M, ed. Chemical senses: appetite and nutrition. Vol. 4. New York: Marcel Decker; 1991, pp. $127-48$.

3. Pettinger C, Holdsworth M, Gerber M. Psycho-social influences on food choice in Southern France and Central England. Appetite 2004; 42: 307-16.

4. Pomerleau J, McKeigue PM, Chaturvedi N. Factors associated with obesity in South Asian, Afro-Caribbean and European women. Int J Obes Relat Metab Disord 1999; 23: 25-33.

5. Chapman I, MacIntosh C, Morley J, Horowitz M. The anorexia of ageing. Biogerontology 2002; 3: 67-71.

6. Hays NP, Roberts SB. The anorexia of aging in humans. Physiol Behav 2006; 88: 257-66.

7. Williams SS, Michela JL, Contento IR, Gladis MM, Pierce NT. Restrained eating among adolescents: dieters are not always bingers, and bingers are not always dieters. Health Psychol 1996; 15: $176-84$

8. Yanovski S. Sugar and fat: cravings and aversions. J Nutr 2003; 133: 835S-7S.

9. Flint A, Raben A, Blundell J, Astrup A. Reproducibility, power and validity of visual analogue scales in assessment of appetite sensations in single test meal studies. Int $\mathbf{J}$ Obes Relat Metab Disord 2000; 24: 38-48.
10. Nordic Nutrition Recommendations 1996 [Nordiske Näringsrekommendationer 1996]. Nord 1996: 28. Copenhagen: Nordisk Ministerråd.

11. Andersen NL, Fagt S, Groth MV, Hartkopp HB, Møller A, Ovesen L, et al. Dietary habits of the Danish 1995 [Danskernes Kostvaner 1995]. Copenhagen: Levnedsmidelstyrelsen; 1995.

12. FAO/WHO/UNU (1985): Energy and protein requirements. Reports of a joint FAO/WHO/UNU expert consultation. Technical Report Series, No. 74. Geneva: World Health Organisation.

13. Raben A, Agerholm-Larsen L, Flint A, Holst JJ, Astrup A. Meals with similar energy densities but rich in protein, fat, carbohydrate, or alcohol have different effects on energy expenditure and substrate metabolism but not on appetite and energy intake. Am J Clin Nutr 2003; 77: 91-100.

14. Geary N. Estradiol and appetite. Appetite 2000; 35: 273-4.

15. Del Parigi A, Chen K, Gautier JF, Salbe AD, Pratley RE, Ravussin E, et al. Sex differences in the human brain's response to hunger and satiation. Am J Clin Nutr 2002; 76: 1017-22.

16. Cornier MA, Salzberg AK, Endly DC, Bessesen DH, Tregellas JR. Sex-based differences in the behavioral and neuronal responses to food. Physiol Behav 2010; 99: 538-43.

17. Smeets PA, de Graaf C, Stafleu A, van Osch MJ, Nievelstein RA, van der Grond J. Effect of satiety on brain activation during chocolate tasting in men and women. Am J Clin Nutr 2006; 83: 1297-305.

18. Schiffman SS, Graham BG. Taste and smell perception affect appetite and immunity in the elderly. Eur J Clin Nutr 2000; 54: S54-63.

19. MacIntosh C, Morley JE, Chapman IM. The anorexia of aging. Nutrition 2000; 16: 983-95.

20. MacIntosh CG, Morley JE, Wishart J, Morris H, Jansen JBMJ, Horowitz M, et al. Effect of exogenous cholecystokinin (CCK)8 on food intake and plasma CCK, leptin, and insulin concentrations in older and young adults: evidence for increased CCK activity as a cause of the anorexia of aging. J Clin Endocrinol Metab 2001; 86: 5830-7.

21. MacIntosh CG, Horowitz M, Verhagen MAMT, Smout AJPM, Wishart J, Morris H, et al. Effect of small intestinal nutrient infusion on appetite, gastrointestinal hormone release, and gastric myoelectrical activity in young and older men. Am J Gastroenterol 2001; 96: 997-1007.

22. Blundell J, MacDiarmid JI. Fat as a risk factor for overconsumption: satiation, satiety, and patterns of eating. J Am Diet Assoc 1997; 97: S63-9.

23. Speechly DP, Buffenstein R. Appetite dysfunction in obese males: evidence for a role of hyperinsulinaemia in passive overconsumption with a high fat diet. Eur J Clin Nutr 2000; 54: 225-33.

24. Cooper JA, Watras AC, Paton CM, Wegner FH, Adams AK, Schoeller DA. Impact of exercise and dietary fatty acid composition from a high-fat diet on markers of hunger and satiety. Appetite 2011; 56: 171-8.

25. King NA, Horner K, Hills AP, Byrne NM, Wood RE, Bryant E, et al. Exercise, appetite and weight management: understanding the compensatory responses in eating behaviour and how they contribute to variability in exercise-induced weight loss. Br J Sports Med 2011 (Epub ahead of print May 19).

26. Jessen A, Buemann B, Toubro S, Skovgaard IM, Astrup A. The appetite-suppressant effect of nicotine is enhanced by caffeine. Diabetes Obes Metab 2005; 7: 327-33.

27. Mineur YS, Abizaid A, Rao Y, Salas R, Dileone RJ, Gündisch $\mathrm{D}$, et al. Nicotine decreases food intake through activation of POMC neurons. Science 2011; 332: 1330-2. 
28. Kadota K, Takeshima F, Inoue K, Takamori K, Yoshioka S, Nakayama S, et al. Effects of smoking cessation on gastric emptying in smokers. J Clin Gastroenterol 2010; 44: e71-e75.

29. Chiolero A, Faeh D, Paccaud F, Cornuz J. Consequences of smoking for body weight, body fat distribution, and insulin resistance. Am J Clin Nutr 2008; 87: 801-9.

30. Kristensen ST, Holm L, Raben A, Astrup A. Achieving 'proper' satiety in different social contexts - qualitative interpretations from a cross-disciplinary project, SOCIOMAET. Appetite 2002; 39: 207-15.

31. Lissner L, Levitsky DA, Strupp BJ, Kalkwarf HJ, Roe DA. Dietary fat and the regulation of energy intake in human subjects. Am J Clin Nutr 1987; 46: 886-92.

32. Raben A, Jensen ND, Marckmann P, Sandström B, Astrup A. Spontaneous weight loss during 11 weeks ad libitum intake of a low-fat/high-fiber diet in young, normal weight subjects. Int $\mathbf{J}$ Obes Relat Metab Disord 1995; 19: 916-23.

33. Saris WHM, Astrup A, Prentice AM, Zunft FHJ, Formiguera $\mathrm{X}$, Verboeket-van de Venne WPHG, et al. Randomized controlled trial of changes in dietary carbohydrate/fat ratio and simple vs complex carbohydrates on body weight and blood lipids: the CARMEN study. The Carbohydrate Ratio
Management in European National diets. Int $\mathbf{J}$ Obes Relat Metab Disord 2000; 24: 1310-8.

34. Bendixen $\mathrm{H}$. Changes in prevalence of overweight, obesity, and slimming behaviour in Danish adults with emphasis on dietary fat quality. PhD thesis. Faculty of Life Sciences, University of Copenhagen, Frederiksberg, Denmark, 2003.

35. Nielsen BM, Nielsen MM, Toubro S, Pedersen O, Astrup A, Sørensen TI, et al. Past and current body size affect validity of reported energy intake among middle-aged Danish men. J Nutr 2009; 139: 2337-43.

\section{*Nikolaj T. Gregersen}

Department of Human Nutrition

Faculty of Life Sciences

University of Copenhagen

Rolighedsvej 30

DK-1958 Frederiksberg C

Denmark

Tel: +4535332696

Fax: +4535332483

Email: ntg@life.ku.dk 